\title{
A construção da significância na e pela voz
}

Daiane Neumann*

\section{Resumo}

Este trabalho busca discutir a construção do objeto voz, a partir da concepção de linguagem enquanto uma antropologia histórica, conforme proposta em Meschonnic (2009), a partir da consideração das reflexões de Saussure e Benveniste. Para fazê-lo, em um primeiro momento, esta pesquisa discute sobre como se dá a relação entre voz e linguagem, a fim de constituir um ponto de vista teórico tanto para a reflexão acerca da linguagem quanto da voz. Em seguida, é colocada em questão a relação que se estabelece entre som e sentido, a partir do ponto de vista adotado no trabalho. Por fim, são levantadas questões referentes a como se dá a construção da significância na e pela voz, em textos e obras. Tal reflexão nos conduz a considerar o ritmo, as rimas, os ecos prosódicos, o silêncio, em uma atividade de escuta da enunciação.

Palavras-chave: Linguagem. Voz. Som. Sentido. Significância.
Le langage n'est pas seulement le lieu et la matière de la communication, il est

avant cela même, et pour être cela, le lieu et la matière de la constituition de chaque être humain dans son histoire.

Le langage est donc indissociablement matière éthique et matière politique. Et matière épique au sens où s'y constituent les aventures de la voix humaine (MESCHONNIC, 2008, p. 222-223).

\section{Introdução}

Proponho-me, neste artigo, a tratar de um tema que tem sido pouco estudado, quando não negligenciado, nos estudos da linguagem: a voz. Conforme o denuncia Parret (2002), a voz teria sido negligenciada tanto nas obras de Jakobson, quanto de Hjelmslev e Troubetzkoy. Segundo o autor, o vocal seria o lugar da alteridade radical, dessa forma, o triunfo

\footnotetext{
Professora do Curso de Letras e do Programa de Pós-Graduação em Letras da Universidade Federal de Pelotas. E-mail: daiane_neumann@hotmail.com
}

Data de submissão: set. 2017 - Data de aceite: out. 2017 http://dx.doi.org/10.5335/rdes.v13i3.7380 
do binarismo em Troubetzkoy e Jakobson levariam à aniquilação da voz.

Essa temática aparece em diferentes domínios do conhecimento, como na filosofia, com Jacques Derrida, em La voix et le phénomène, e Adriana Cavarero, em Vozes Plurais; na literatura, com Paul Zumthor, em Introdução à poesia oral; na antropologia, com David Le Breton, em Éclats de la voix; e nos estudos da linguagem, com Ivan Fónagy, em $L a$ vive voix, e Herman Parret, em La voix et son temps. No entanto, mesmo que Ivan Fónagy e Parret tratem da voz nos estudos da linguagem, o fazem em interface e diálogo com outros campos do conhecimento, o primeiro observa a voz sob a perspectiva cotidiana, artística, psicopatológica e ontogenética; enquanto o segundo sob a perspectiva da semiótica, da psicologia da percepção, da retórica, da musicologia.

A reflexão proposta, aqui, contudo, busca pensar a voz do ponto de vista de sua relação com a linguagem. Mesmo que os autores anteriormente elencados lancem mão de uma concepção de linguagem para a construção do objeto voz - conforme será discutido ao longo do trabalho -, é justamente a alteração dessa concepção de linguagem que promove a constituição de um novo objeto de pesquisa.

Como nos ensina Meschonnic (1989/2006, p. 56-57), "l'idée que vous avez du langage est votre portrait", isto é, a visão que sustentamos de linguagem é nosso retrato, porque revela não apenas o que pensamos sobre a língua/ linguagem, mas também nossa concepção de sujeito, de subjetividade, da relação entre subjetividades, da relação do homem com a língua, com ele mesmo, com o outro, com o mundo, com a cultura, com a sociedade.

Ademais, mesmo no conjunto da obra de Henri Meschonnic, não há uma discussão mais sólida sobre a voz. Não há, dentre as suas inúmeras obras, nenhuma que tenha sido consagrada à reflexão sobre a voz, apenas um capítulo da obra Critique du rythme, que se chama "Le poème et la voix", no qual não há, no entanto, uma discussão mais coesa e aprofundada sobre o tema, mas reflexões esparsas acerca da relação da voz ora com o texto literário, ora com o ritmo. Além disso, na obra supracitada, o teórico da linguagem (2009, p. 288) afirma que "a antropologia do ritmo, da linguagem, requer uma antropologia histórica da voz"1.

A construção da voz se dá, neste artigo, justamente por partir de uma discussão entre voz e linguagem, considerando o que Meschonnic (2009, p. 288) denominou de "uma antropologia histórica da linguagem", que se propõe como uma continuidade da reflexão iniciada por Saussure e Benveniste. Para além da construção desse objeto, busco discutir sobre como se dá a construção da significância, a partir da observação do elemento da voz em textos e obras.

Para desenvolver tal proposta, em um primeiro momento, discuto sobre como a 
relação entre voz e linguagem é concebida neste trabalho, a fim de constituir um novo objeto. Em seguida, proponho uma reflexão em torno da relação entre som e sentido, já que a partir dessa concepção de linguagem e de voz, há uma alteração na forma como se concebe essa relação. Por fim, trato da construção da significância na voz.

\section{A voz e a linguagem}

Em geral os estudos da voz concebem-na enquanto fônica. Mesmo que Derrida (1994) a observe mais como uma voz interior, uma voz da consciência, também faz referência a ela enquanto fônica. Os olhares para essa voz são diversos, a grosso modo, pode-se dizer que Parret (2002) e Fónagy (1983) buscaram pensar mais uma estética da voz, considerando a tradicional divisão feita pelos estudos da pragmática, entre sentido, pragmática $\mathrm{e}$ estética. Zumthor (1997) busca pensar uma poética da oralidade, refletindo sobre o que é específico da poesia oral. Cavarero (2011) e Le Breton (2011) se interessam mais por pensar a unicidade, a singularidade da voz.

Neste artigo, busco também pensar a voz concebendo-a enquanto elemento mais íntimo, mais singular, mais subjetivo. De acordo com Flores e Surreaux (2012, p. 94), "a voz é, na enunciação [...] o que singulariza cada um na gramática de uma língua", "o processo de entrada em uma língua se dá na proporção em que o falante experiencia, cada vez mais, um afunilamento dessa própria língua, chegando, inclusive, a enunciá-la à sua própria e única maneira" (p. 94). Meschonnic atenta ainda para o fato de que

[...] a voz, que parece o elemento mais pessoal, mais íntimo, é, como o sujeito, imediatamente atravessado por tudo o que faz uma época, um meio, uma maneira de situar a literatura, e particularmente a poesia, tanto quanto uma maneira de se $\operatorname{situar}^{2}(2009$, p. 284-285).

No entanto, não considero a voz necessariamente enquanto som, mas sim e principalmente em seu caráter singular, único e particular, o que só pode ser feito, de acordo com o ponto de vista aqui adotado, em uma perspectiva que pense o discurso.

Ao pensá-la sob o ponto de vista do discurso não é possível que se pense a voz senão em sua relação intrínseca com a linguagem. A noção de linguagem aqui adotada não concebe o homem como estando fora da linguagem, pois o homem seria construído, constituído de linguagem; não nasceria, pois, na natureza, e sim na cultura. A consequência disso é que não se pode conceber que haja voz sem linguagem, conforme postulam Parret (2002) e Fónagy (1983), ao pensar sobre uma "voz antes da linguagem" e "depois da linguagem", assim como não se pode conceber que haja linguagem sem voz.

Tal noção de linguagem também é o que permite aqui pensar sobre o fato de a voz ser concebida como o elemento mais íntimo, mais singular, mais subjetivo, pois, nela, a subjetividade, mais 
especificamente, a intersubjetividade, é observada enquanto constituidora e construtora da linguagem. Há em tal concepção uma relação intrínseca entre linguagem e subjetividade. Consequentemente, se a voz não pode ser pensada sem a linguagem, então a voz também é constituída e construída pela subjetividade. Não se pode, portanto, dissociar linguagem, voz e subjetividade.

Há na concepção de voz enquanto som, segundo Meschonnic (2009), uma confusão entre subjetividade e individualidade, subjetivismo e individualismo. Ainda segundo o autor (1989/2006), a confusão entre a voz e o fônico seria solidária da mesma confusão que identifica o ritmo enquanto fônico. Para pensar uma definição não mais fisiológica, nem psicológica, mas cultural, histórica e poética da voz, é preciso que se deixe a dualidade do oral e do escrito e se passe a uma tripartição, do escrito, do falado e do oral ${ }^{3}$. Tal debate só pode ser erigido a partir de uma antropologia histórica da linguagem.

A partir de tal perspectiva também a voz não pode ser oposta ao silêncio, pois haveria ainda linguagem no silêncio da voz, na medida em que não há silêncio de fala, por exemplo, fora da voz, da possibilidade da voz. Conforme Heidegger (apud MESCHONNIC 1989/2006, p. 311), se calar não significa estar mudo, menos ainda não ter linguagem. Há, portanto, voz no silêncio, e silêncio na voz, tal silêncio também constitui o sentido, a significação. Não é possível que se pense um "fora da linguagem", isso significa que o silêncio faz parte dela.

Pensando a linguagem, a voz e a subjetividade como elementos que se constituem mutuamente, que fazem parte da mesma problemática, podemos afirmar que ao nos debruçarmos sobre os discursos não é mais o som que escutamos, mas o sujeito. Tal concepção de linguagem e de voz coloca o analista numa atividade de escuta da enunciação, tanto quando se depara com textos falados, quanto com textos escritos.

A voz ainda pode ser concebida como metáfora da originalidade mais íntima, o que se percebe, por exemplo, ao se fazer referência à voz em uma obra ou de um escritor. É o que se observa nessa passagem de Simone de Beauvoir ${ }^{4}$ (apud MESCHONNIC 1989/2006, p. 320-321, tradução nossa),

[...] a literatura só começa nesse momento, no momento em que eu escuto uma voz singular [...] não há literatura se não houver uma voz, portanto uma linguagem que porte a marca de alguém. É preciso um estilo, um tom, uma técnica, uma arte, uma invenção [...] é preciso que o autor me imponha a sua presença; e quando ele me impuser a sua presença, ao mesmo tempo estará me impondo seu mundo ${ }^{5}$.

O que interessa nesta reflexão não é criticar essa metáfora, mas compreender de onde ela vem, na medida em que busco pensar como se faz essa passagem do sujeito-voz e da voz-sujeito através da oralidade dos textos; o que pode ser observado desse sujeito-voz e dessa voz-sujeito nos textos, como tais observações contribuem para pensar essa metáfora. 
Trata-se de observar como a articulação entre som e sentido faz para construir o que constrói, para dizer o que diz, para constituir isso que será chamado de "voz do autor".

A voz, assim como a linguagem, não raro é tratada como um instrumento. $\mathrm{O}$ tratamento da voz enquanto puramente fisiológica e biológica tende a compreendê-la enquanto instrumento, enquanto ferramenta de expressão de si, de afirmação de si; a voz cantada não raro é tratada como um instrumento de música. Tal postura é o que se pode ver em Arnaud $^{6}$ (apud MESCHONNIC 1989/2006, p. 318) "qualquer outra ferramenta que não a voz pode ser consertada, qualquer outro instrumento substituído. Uma voz perdida não retorna, quebrada, ela não se refaz." A comparação da voz com um instrumento, assim como a comparação da linguagem com um instrumento é antiga, encontra-se mesmo na Encyclopédie (apud MESCHONNIC 1989/2006, p. 319), "os órgãos que formam a voz fazem uma espécie de instrumento ao vento", e na Encyclopedia Universalis, "a voz, primeiro dos instrumentos, permite ao pensamento transformar-se em estruturas cantadas ou faladas."'.

No entanto, trata-se aqui de fazer o que dizia Saussure ${ }^{10}$ (apud MESCHONNIC, 1989/2006, p. 318), “despojar o problema de tudo o que é puramente fisiológico"11. Dessa maneira, não concebo aqui nem a voz nem a linguagem como instrumento. Conceber a linguagem como instrumento é instrumentalizar a voz, assim como conceber a voz como instrumento é instrumentalizar a linguagem. Tal instrumentalização da linguagem e da voz é o que denuncia o pensar uma antropologia histórica da linguagem, uma antropologia histórica da voz.

Ao pensar a voz e a linguagem enquanto significante e significado, enquanto necessários um ao outro, cessa a possibilidade de que se oponha voz e linguagem, que se oponha uma irracionalidade à racionalidade. Tal oposição nasce da filosofia de Platão, conforme nos mostra Cavarero (2011), ao dizer que o filósofo mostra desconfiança em relação à sonoridade, e que tal desconfiança tem um propósito claro de garantir a supremacia de um logos fundado na clareza do conceito contra os efeitos não só diversivos como perigosos de uma palavra misturada ao som. Essa oposição entre a racionalidade e a irracionalidade é o que leva à oposição entre a linguagem e a vida, à consideração da linguagem enquanto instrumento de comunicação, a partir de um olhar pragmático.

A voz, assim, "pode fazer sua sintaxe, seu ritmo, pode fazer sua tipografia" 12 (MESCHONNIC 1982, p. 21). O autor ainda sugere que uma poética da tipografia e do visual poderia mostrar essa relação entre o oral e o visual, a fim de elucidar o que fazem certas práticas poéticas ou romanescas; em especial a poesia moderna que começou uma relação nova entre o visual e o oral, o que transformou a escrita. 
Pensar, então, uma antropologia histórica da voz significa pensar a voz como uma problemática que não pode estar alheia à problemática da linguagem e da subjetividade. O termo antropologia nesse sintagma estabelece que a voz é o lugar de constituição dos sujeitos, de subjetividades, ou, mais propriamente, de intersubjetividades, na medida em que como ensina Benveniste (2006a), ao se enunciar o "je" estabelece uma outra pessoa, ao qual esse "je" diz "tu" e que diz "tu" ao "je". Tais termos não podem ser concebidos um sem o outro, são, portanto, complementares.

A partir da voz, observada enquanto antropológica, os sujeitos se constroem na e pela voz, e a voz no e pelos sujeitos, na empiricidade do discurso. É por meio da voz que se percebe a constituição da subjetividade, da intersubjetividade e da trans-subjetividade. Essa subjetividade resulta da transformação do que se considera sentido ou valor na língua em valores no discurso e somente no discurso, em quaisquer níveis linguísticos.

Trata-se aqui de considerar radicalmente a proposta de Benveniste quando esse diz que o locutor "apropri[a]-se da língua toda designando-se como eu" (2005, p. 288). Lê-se aqui o "apropriar-se" como um tornar seu, tomar a língua a partir de uma subjetividade, isto é, a subjetividade não está somente no uso do pronome je, mas na língua toda. Por isso, os valores passam de valores da língua, para valores do discurso e somente do discurso, dessa forma, o discurso tor- na-se um sistema de valores, que não é fechado, nem acabado, no sentido de que a produção da significância aí é infinita, pois é sempre passível de construir novos sentidos, a partir de novas leituras. A subjetividade seria aí, pois, toda diferencial, toda sistemática.

No entanto, para isso, é preciso deixar o mundo do signo "que existe em si, funda a realidade da língua, mas [...] não encontra aplicações particulares", enquanto a frase, leia-se discurso, "expressão do semântico, não é senão particular" (BENVENISTE 2006b, p. 230, grifo do autor).

Trata-se de integrar o discurso na voz e no corpo, e a voz e o corpo no discurso, em que se percebe uma semântica da significância generalizada, do contínuo no descontínuo. Assim, o termo "histórica" intervém aqui como uma oposição ao que Meschonnic chamou de "historicismo" (MESCHONNIC 2009, p. 29). "Histórica" aqui está ligada estreitamente à noção de "antropologia", pois o sujeito se constitui e se constrói por meio de um processo de historicização que acontece no e pelo seu discurso.

De acordo com o autor (2009), o historicismo seria o esquecimento de que nada da linguagem e da história é descrito sem observador e que a observação é sempre uma relação que modifica o que se observa. A historicidade teria, dessa forma, rejeitado o historicismo. Tal rejeição teria se iniciado com Saussure, quando esse propõe o primado do valor, e não do sentido, do sistema, e não da 
nomenclatura da palavra compreendida por sua etimologia, do funcionamento, e não da origem, e do signo radicalmente arbitrário, e não da oposição entre natureza e convenção. Para o autor (2009), esses quatro termos - valor, sistema, funcionamento, arbitrário - determinam em conjunto a hipótese do primado do discurso, que não foi formulado por Saussure, mas que ele tornou possível.

É Benveniste quem toma tais noções em conjunto, pois é o único a compreender o pensamento de Saussure como um pensamento que entende a língua como um sistema, e não como estrutura, assim, encontra-se no seio de um novo espaço teórico por ele aberto com a proposta do sistema linguístico da enunciação. Nesse novo espaço teórico, Benveniste afirma que a linguagem "re-produit la réalité" (1974a, p. 25), o que não significa repetir, copiar, mas sim que a realidade é produzida de novo mediada pela linguagem. Isso quer dizer que a significação não pode ser pensada fora do discurso, fora do simbólico, pois a linguagem mediatiza a relação do homem com a realidade. Dessa forma, Benveniste acaba por propor que o processo de historicização se dá na e pela linguagem, que só se pode construir a história na e pela linguagem.

A voz pensada na e pela linguagem e a linguagem na e pela voz, nos leva a admitir que a voz é o lugar em que se dá o processo de historicização de uma subjetividade. Chegamos, assim, ao princípio de que não há somente um dizer e um dito na voz, mas também um fazer.
Ao nos enunciarmos, mais do que dizendo, estaríamos fazendo alguma coisa, o que subverte a tradicional separação proposta entre semântica, pragmática e estética. Todos esses níveis aparecem, portanto, englobados no processo de construção da significância, já que a produção de um discurso é concebida como uma ação sobre o mundo, em que indivíduo e sociedade se determinam mutuamente. Além disso, o ato estético passaria a ser considerado um ato ético.

Sendo a voz, então, o sujeito, é a necessidade e a ficção do indivíduo (MESCHONNIC, 1995). Essa ficção não seria considerada como uma mentira, conforme o quer uma poética mais tradicional, mas antes, figuraria como a sua própria história, que o sujeito conta a ele mesmo, para se encontrar. A voz seria o lugar dessa busca, por isso, ela é o lugar da construção da subjetividade, da intersubjetividade, o lugar da alteridade radical, conforme propõe Parret (2002).

A voz seria o lugar privilegiado da subjetividade, na medida em que a linguagem também o é. A voz e a linguagem constituem as duas faces de uma mesma moeda, o verso e o reverso da folha de papel. Não é possível, portanto, que se separe nos estudos da linguagem o som e o sentido, ou que se conceba o primado de um sobre o outro. A discussão acerca dessa relação será aprofundada na seção seguinte. 


\section{A relação entre o som e o sentido}

Parece-nos evidente que na linguagem há o som e o sentido; há o som da voz, como o som da música; há os sons abertos, os sons fechados. No entanto, o som não é o mesmo na voz, nos barulhos ou na música, nem mesmo o sentido do que se concebe enquanto som, assim como o sentido na linguagem se constitui como em nenhum outro lugar, nem na música, nem na pintura.

Essa discussão se encontra em Benveniste, quando o linguista, seguindo a reflexão de Saussure sobre a semiologia, afirma por meio da proposição do "PRINCÍPIO DE NÃO REDUNDÂNCIA entre sistemas" que não se pode "dizer 'a mesma coisa' pela fala e pela música” (2006a, p. 53), que seriam dois sistemas de base diferente. Dessa forma, observa-se que dois sistemas semióticos de tipo diferente não são mutuamente conversíveis. A fala e a música, por exemplo, têm certamente este traço em comum, a produção de sons e o fato de se dirigirem ao ouvido, no entanto,

[...] esta relação não prevalece contra a diferença de natureza entre suas unidades respectivas e entre seus tipos de funcionamento (2006a, p. 54).

A história dos estudos linguísticos mostra uma dualidade, uma heterogeneidade entre o som e o sentido. Embora haja tentativas de associar o estudo de um ao outro, ou de mostrar que as línguas associam o sentido ao som, em geral, se concebe o som mais o sentido. Na esteira de Meschonnic (2009), o fechamento estruturalista do tempo levaria a uma anulação desse, na medida em que a percepção do fluxo seria suprimida. Da mesma forma, o formalismo do som deduziria de Saussure que não há "nenhuma relação entre forma e conteúdo no texto", visto que "só no espírito do leitor é que reside essa união, e não no poema"13 (GAUTHIER 1974, p. 10 apud MESCHONNIC, 2009, p. 208). Tal linguística acabaria por buscar suas estruturas no poema e falsearia o termo significante, pois ela o transformaria em um recipiente.

Essa versão do dualismo seria exatamente do que o trabalho de Saussure teria buscado se distanciar. Saussure (2004) mostra que os dois elementos, significante e significado, são inseparáveis, o que fica evidente na construção de conceitos como o de valor, de sistema e de funcionamento no arbitrário; conceitos esses que tornam possível que se pense uma historicidade da linguagem e, portanto, uma poética dessa historicidade.

Percebemos essa postura de observar som e sentido sob o paradigma binário em autores que, em geral ao tratar a linguagem, concebem-na enquanto língua, enquanto unidades descontínuas que serão transpostas para o discurso. Assim, o sentido passa a ser concebido como algo que poderia ser acrescentado ao som ou até mesmo a outro sentido já estabelecido anteriormente. Tal postura fica evidente em Fónagy (1983) quando 
esse propõe que haveria uma mensagem primária que seria transformada por um modulador e que o estilo verbal seria uma mensagem secundária engendrada com a ajuda de um sistema de comunicação pré-verbal e integrado à mensagem linguística. Para o autor, as mensagens semânticas estariam nas estruturas abstratas, enquanto as mensagens estéticas nas realizações concretas.

Zumthor (1997) pensando por intermédio de uma concepção de linguagem também no paradigma do signo, postula que o phôné não se uniria imediatamente ao sentido e que haveria um duplo desejo na fala, o de comunicar uma informação e o de submeter o interlocutor à força ilocutória. Há nessa proposição uma clara distinção entre semântica e pragmática, o que propõe também que se pense em um acréscimo de sentidos.

Le Breton (2011) sugere que a expressão vocal contradiz o enunciado ou o precisa, como se houvesse um sentido atribuído pela língua, e à voz coubesse acrescentar sentidos a um enunciado já carregado de sentidos, o que comprova que $o$ autor concebe a linguagem a partir do paradigma do signo, do descontínuo, e não enquanto discurso, enquanto contínuo.

Proponho aqui que se pense a construção de sentidos no âmbito do discurso, em que tal construção sempre será nova, particular e singular. Quando analisamos o discurso, a partir de um olhar do semântico sem semiótico ${ }^{14}$, é impossível que possamos perceber aquilo que é do domínio exclusivamente da linguagem e aquilo que é do domínio exclusivamente da voz. No contínuo do discurso, é a relação de imbricação entre ambos que constrói a significância do texto.

Não há a partir do ponto de vista do semântico sem semiótico, níveis de acentuação, níveis de produção de sentido, ao contrário, este é percebido enquanto transversal à linguagem, ao discurso. Dessa forma, ao mesmo tempo em que a entonação é fonológica, é também aquilo que escutamos do sujeito em sua linguagem. Ela é a presença do sujeito no discurso, seu modo de intervenção, que porta, engloba, transborda e também pode contradizer o sentido das palavras. Não se trataria, conforme Meschonnic (2009), somente da emoção, entraria aí a relação do sujeito com sua psique, sua história.

A voz concebida como mais do que uma simples portadora de palavras, um simples órgão de fala, seria o lugar em que sentiríamos a presença do corpo, do corpo-sujeito, do corpo histórico e social. Nesse sentido, conforme lembra Meschonnic (1989/2006), é interessante pensar que essa relação entre voz e sujeito também aparece mesmo na gramática quando se fala em voz ativa, voz passiva, pronominal.

A proposta aqui do estudo da voz é, portanto, partir de uma concepção bastante saussuriana de que seria impossível separar o som e o sentido, ou conceber um ou outro enquanto a priori, e trazer as noções que foram utilizadas 
para pensar o sistema da língua, pelo mestre genebrino, como a noção de valor, sistema, funcionamento ligados pelo arbitrário, para o discurso. $\mathrm{O}$ discurso é concebido então como um sistema de valores arbitrários, em que não há um $a$ priori do som ou do sentido, o que torna cada vez mais difícil que se estabeleça uma distinção entre o falado e o escrito, do ponto de vista do funcionamento linguístico.

É importante nesse momento resgatar a noção de oralidade que estabelece, segundo o ponto de vista aqui adotado, uma espécie de continuidade entre o texto escrito e o texto falado e relembrar as palavras de Ruth Finnegan, utilizadas por Meschonnic (1989/2006), ao afirmar que a distinção entre poesia oral e escrita que se conhece parte de critérios estabelecidos pela sociologia e que, do ponto de vista poético, haveria uma impossibilidade de fundar uma distinção entre as duas modalidades. A autora diz ainda que "do ponto de vista linguístico, oral ou escrito, um texto permanece um texto"15 (FINNEGAN, ${ }^{16}$ p. 125 - MESCHONNIC 1989/2006, p. 333).

Não se trata de afirmar que não há particularidades, especificidades na produção da poesia oral em relação à produção da poesia escrita. É, no entanto, imperativo que se atente para o fato de que na poesia escrita há também aspectos suprassegmentais que merecem a observação do analista, na medida em que podem portar todo o sentido, mais do que as palavras. Além disso, confor- me Zumthor (1997), sustentando-se em Jakobson, há aspectos prosódicos e acentuais analisados no âmbito da poesia oral que são próprios da linguagem, como um todo, ou seja, estão presentes também no sistema da escrita. Tal análise torna-se viável na medida em que não se exclui a possibilidade de que haja voz no texto escrito.

Embora haja particularidades na produção de um poema oral em relação ao poema escrito, não é possível que se estabeleçam critérios cerrados entre o que pertence ao domínio da escrita e o que pertence ao domínio do falado, pois, segundo o ponto de vista linguístico, a linha que separa os dois domínios é muito tênue e frágil. Tal linha tende a se tornar mais vulnerável ainda quando o analista se debruça sobre o texto a partir do ponto de vista do discurso, pensando a relação entre o domínio semântico e semiótico, entre a linguagem e a voz, enquanto interna a um texto, a uma obra particular.

A partir das considerações apresentadas, nesta seção, acerca da relação entre o som e o sentido, passo para a discussão sobre a construção da significância na voz.

\section{A voz e a significância}

A noção de significância é utilizada por Benveniste no texto "Semiologia da língua", ao comparar o funcionamento do sistema da língua com outros sistemas - como o da música e da pintura, por exemplo -, a fim de apontar o que 
é específico da língua ${ }^{17}$. Assim, o linguista afirma que a língua "é investida de uma DUPLA SIGNIFICÂNCIA", pois combina dois modos distintos de significância, "o modo SEMIÓTICO” e o "modo SEMÂNTICO” (2006a, p. 64). Discutindo sobre o que chamou de sistema de discurso, Meschonnic (2009) retoma o uso dessa expressão, para referir-se à significância que é construída a partir de elementos prosódicos e acentuais que passam por todos os níveis da linguagem, morfológico, sintático, lexical.

De acordo com Meschonnic (1989/2006), se o sentido está nas palavras, e a significância no ritmo e na prosódia, consequentemente a significância está também na voz. Pela voz, a significância precede 0 sentido, o porta, na medida em que é o discurso que faz o que em seguida será atribuído às palavras. $A$ voz precede $e$ porta os termos, o que torna possível a entonação. Compreender precede o sentido.

A voz figura, então, como a organização, a disposição, a configuração do discurso, o que a torna inseparável do sentido desse discurso. A voz organizaria o sentido no discurso, dessa forma, ela não pode ser concebida como um nível; ela não acrescenta sentidos, visto que a significância é transversal ao discurso, se faz no e por todos os elementos do discurso.

Pensando a problemática da voz estreitamente ligada à problemática da linguagem, que por sua vez figura aqui enquanto antropológica, ou seja, concebida enquanto indissociável do sujeito, pode-se afirmar que a voz é a organização do sujeito no discurso, o sentido é uma atividade do sujeito. A voz pensada no e pelo discurso, e o discurso pensado na e pela voz seria uma teoria do sujeito na voz. Parafraseando Meschonnic (2009) quando esse diz que o sujeito seria comparável à origem da linguagem, poder-se-ia dizer aqui que o sujeito seria comparável à origem da voz.

A subjetividade é concebida como toda diferencial, toda sistemática, na medida em que a subjetividade de um texto resulta da transformação do que é valor na língua em valores no discurso e somente no discurso, em quaisquer níveis linguísticos. O discurso é sistema. A escrita, portanto, produz uma retomada indefinida de leitura, o que transforma essa subjetividade em uma intersubjetividade, em uma trans-subjetividade, mas não uma intrassubjetividade. Tal enunciação não resulta somente de um enunciado, mas de uma cadeia de re-enunciações.

Por isso, a análise que se faz do texto a partir da perspectiva aqui proposta para o estudo da linguagem e da voz não consiste em comentar um verso ou um poema com o objetivo de esgotar-se em comentários acerca do seu valor, do seu sentido, mas, ao contrário, discutir como um texto significa e a situação desse como. Essa análise busca a especificidade do modo de significar de um texto, por isso, há relação entre a voz e a significância. 
A voz figura, pois, como o lugar privilegiado da aventura antropológica, o lugar da produção de sentidos novos, as visões, as metáforas se fazem nela. A voz pensada pelo discurso passa a ser percebida como atividade dos sujeitos. $\mathrm{Na}$ organização desse sistema de discurso, os sentidos são organizados a partir da relação sintagmática e paradigmática que perpassa todos os níveis linguísticos, o que significa, de acordo com Meschonnic (2009), que o sentido não pode ser dividido segundo as subdivisões tradicionais (sintaxe, léxico, morfologia) que foram criticadas por Saussure.

Nesse sistema de discurso, nesse sistema de valores, em que a significância é dada por essa relação sintagmática e paradigmática, não há como separar o discurso da voz e a voz do discurso, os dois são inseparáveis, um constitui o outro, de uma só vez. Dessa forma, todos os elementos, todas as unidades presentes no discurso contribuem para a organização do sentido da voz.

A voz representa uma passagem, uma passagem do sujeito no discurso e na voz, a passagem do sentido e da significância, do fazer sentido, em cada elemento do discurso, em cada consoante, em cada vogal. O discurso é visto, então, como um fluxo, é a estruturação de um sistema que não é ainda sistema, pois não se reconhece como um, na medida em que está aberto, inacabado, em curso. Contra a observação da linguagem a partir tão somente de sua linearidade, a voz figura como um plural interno, uma simultaneidade.
A prosódia, segundo Meschonnic (2009), enquanto elemento de significância, torna-se subjetiva, trans-subjetiva, ou seja, construída para produzir o sujeito no e por um texto. De acordo com Appollinaire (1966, p. 782 apud MESCHONNIC 2009, p. 267), “e, se pesquisarmos na obra de cada poeta uma personalidade, não nos surpreenderemos de encontrar as prosódias pessoais"18.

A prosódia figura como inseparável do valor, que é construído pelo poema. Conforme aponta Meschonnic (2009), as palavras, observadas isoladamente, têm apenas seus sentidos, somente o paradigmático e o sintagmático próprios de cada poema fazem o trabalho poético e constroem o valor de cada palavra, em um determinado sistema de valor, produzido por uma obra particular. Outras leituras da mesma obra são possíveis, indefinidamente, na medida em que a significância é infinita, assim como a teoria. O primado da voz contribui para o sentido da não totalidade, da não verdade.

A problemática da oralidade é uma problemática que interessa ao pensar a voz, na medida em que aquela é a relação necessária, num discurso, do primado rítmico e prosódico de seu modo de significar. Tal oralidade também está ligada à coletividade e à historicidade.

A voz se apresenta, na esteira dos estudos de Meschonnic (2009), como diversa nas diferentes línguas, nas diferentes culturas. Dessa forma, apren- 
der uma língua estrangeira significa mudar de voz. A tarefa do tradutor se complexifica também ao pensar que no processo de significância do texto, há de se considerar a voz, há de se considerar os aspectos prosódicos e acentuais das línguas. Aquele que fala e a sua fala não são separáveis e são situados historicamente.

Há uma voz própria de cada língua, o que não significa que a língua em si tenha voz, mas suas palavras, suas frases, seus discursos. Há um conjunto de condições, de aspectos prosódicos e acentuais que caracterizam a voz de uma língua. Aprender uma língua é submeter-se a um novo conjunto de aspectos prosódicos e acentuais, que nos levam a mudar de voz.

À voz são atribuídos os mesmos caracteres que são atribuídos ao ritmo, de acordo com o autor (2009), a altura, a intensidade, o timbre, a entonação. No entanto, a voz teria também seus caracteres próprios, físicos, fisiológicos; ela seria feminina, masculina, jovem, madura, senil, plena ou branca, quente ou ácida. A voz pode ser vigorosa ou sofrida, delicada, quebrada, fresca, rouca, pesada. Como há enunciação e enunciador na voz, ela poderia ser enunciada ou percebida pelo outro como uma voz encantadora, emotiva, tensa, doce, seca, irônica, brusca, delirante, suplicante, polida ou grosseira. A voz unificaria, se assemelharia ao sujeito, a sua idade, seu sexo, seu estado.
Há um erotismo da voz, na medida em que há um sexo da voz, que faz mais do que denominar seu caráter sexual secundário, personalizado e misturado a toda a significação. A inflexão, através de sua relação constante com a voz, tem como a fala, charme ou repulsão (MESCHONNIC, 1989/2006).

A partir da análise da voz contribui-se para pensar uma teoria do discurso, na medida em que se observam as possibilidades de uma língua pelo seu discurso e as possibilidades de discurso pela língua, os quais são ao mesmo tempo culturais e linguísticos. A voz de uma língua está ligada a seus aspectos prosódicos e acentuais, a seu ritmo, por isso, ela está nos discursos e se transforma com eles.

Pensar a linguagem e a voz enquanto uma antropologia histórica significa compreender tudo o que a linguística deixaria para a situação, ou seja, o discurso é composto pelo extralinguístico tanto quanto pelo linguístico. Isso significa que falar com as mãos faz parte da linguagem, como todo o corpo, mover-se, tocar-se, segundo as culturas, segundo os modos de relação. Essa antropologia da linguagem seria dupla, segundo o falado e segundo o escrito, a oralidade não é a mesma, a voz não é a mesma. O que é diretamente acessível à antropologia no falado passa diretamente pelo escrito por uma poética que situe os modos de significância. Esses modos de significância são construídos por intermédio da acentuação, da prosódia, do ritmo, das rimas, dos ecos prosódicos, dos silêncios. 
Conforme nos lembra Meschonnic (1982), o corpo emite signos, ou melhor, infrassignos, dos quais a voz é um. $\mathrm{Na}$ voz não haveria então somente a prosódia no sentido linguístico - variações de intensidade, de alongamento, de altura -, mas o corpo, os signos do corpo. Numa perspectiva de um contínuo antropológico, o gesto, com o corpo e a voz, é reintroduzido na linguagem. $\mathrm{O}$ gesto "mesmo redundante (o que é frequentemente o caso) traz afirmações que não são fornecidas pelo enunciado e sobre as quais nós podemos nos perguntar se não são, na verdade, o essencial da mensagem"19 (CALAME-GRIAULE ${ }^{20}$ apud MESCHONNIC 1982, p. 131).

$\mathrm{O}$ gesto e a voz são integrados a um conjunto sintético no estudo da comunicação não verbal, de acordo com Meschonnic (1982). Dessa forma, não se trata de pensar uma linguagem dos gestos ou por gestos, mas em uma linguagem enquanto um sistema de comunicação heterogêneo que é ao mesmo tempo verbal e corporal, o que inclui contatos cutâneos, carícias, calor, movimento, odores, mímicas, emissões sonoras, etc. Tal concepção levaria Jacques Cosnier a criticar a expressão linguagem do corpo enquanto oposta à linguagem verbal, pois toda a linguagem, para o autor, seria uma linguagem do corpo, sendo ela verbal e/ou corporal, na medida em que o processo enunciativo seria sempre um processo corporal.
Partindo de uma "gestique de l'énonciation” ${ }^{21}$, Cosnier não vê no gesto em relação à linguagem

[...] nem um auxiliar, nem um derivado, mas um associado que lhe é estreitamente intrincado para formar a linguagem natural assim composta de três subsistemas maiores: o verbal, o vocal, o gestual ${ }^{22}$ (COSNIER, 1982, p. 281 apud MESCHONNIC 1982, p. 22).

Assim, Meschonnic (1982) propõe que se observe o que ele chamou de dêiticos prosódicos, rítmicos, que estariam no plano rítmico e prosódico do discurso. Esses dêiticos prosódicos teriam o mesmo papel dos gestos na gramática do texto falado e se constituem a partir da organização da acentuação do texto, quando, por exemplo, há relações estabelecidas por elementos, como a rima, os ecos prosódicos, a partir da observação da paradigmática e sintagmática do texto.

Não seria mais então somente na comunicação precoce das crianças em seu entorno maternal e familiar que os contatos pele a pele, as trocas de olhares, o banho sonoro e a melodia da voz seriam importantes e imprescindíveis. Tais gestos, tal presença do corpo seria algo que englobaria a linguagem como um todo, que faria parte dela como um todo. Da voz ao gesto, até a pele, todo o corpo se torna ativo no discurso. No entanto, conforme lembra Meschonnic (1982), trata-se de um corpo social, histórico, tanto quanto subjetivo.

O teórico da linguagem (1982) lembra ainda que Mauss, em seu estudo sobre as práticas do corpo, já havia mostrado que o corpo é histórico e cultural. Esse 
corpo, no entanto, enquanto conjunto de relações sociais não se opõe a um corpo sujeito, pelo contrário, a partir de uma antropologia histórica da voz, eles são percebidos enquanto constitutivos um do outro. A voz não seria, assim, uma oscilação entre o corpo e a linguagem, mas uma solidariedade implícita entre o discurso sobre a voz e a teoria da linguagem.

Não se trata aqui, no entanto, de considerar a voz em relação a um corpo enquanto biológico e/ou psicobiológico, como o faz Fónagy (1983), ao afirmar que se estabelece sobre um plano pré-consciente uma relação entre a doçura, por exemplo, e a ondulação da articulação neutra e que a palatalização seria, então, a expressão de uma atitude doce ou adocicada nas diferentes línguas. $\mathrm{O}$ autor afirma ainda que a cólera e a raiva aumentariam consideravelmente a tensão muscular, prolongariam a duração da oclusão e estreitariam o canal bucal durante a articulação de consoantes fricativas; por outro viés, uma constrição laríngea não violenta, menos intensa, juntamente a uma constrição faríngea, acompanharia as lágrimas e, por extensão, a queixa, a comiseração.

O ouvido não seria somente sensorial, mas também cultural e histórico, de acordo com Meschonnic (1989/2006), ou seja, ele é um órgão social. Dessa forma, não se trata de negar um desejo mimético no uso da linguagem, mas é importante que não se privilegie um olhar biológico e/ou psicobiológico sobre a língua.
Essa física do discurso, que dissemina e corporaliza o sentido, dissemina e corporaliza o sujeito, segundo Meschonnic (1982). A escuta analítica ou poética não seria somente assim um olhar sobre as diferentes organizações do sentido, mas ela participaria de todo o corpo.

Freud, em seu estudo sobre a histeria, permite que se desmetaforize a metáfora da relação entre linguagem e corpo, pois o psicanalista coloca em evidência um efeito da linguagem sobre o corpo, um aspecto da relação entre linguagem e corpo. A histeria mostra o poder da linguagem sobre o corpo, tanto quanto seu caráter corporal, donde Meschonnic (1989/2006) pressupõe que algo do corpo seja necessário para que haja o poder da linguagem. A presença da voz na linguagem é a presença do corpo na linguagem, do máximo possível do corpo e de sua energia. Assim, a voz faz o inverso da histeria, pois mostra a presença do corpo na linguagem.

É porque o corpo é mais engajado na linguagem quando o ritmo, os aspectos prosódicos e acentuais, tem papel maior, compreendendo que a poesia é o modo de significar que fala mais, que transforma mais os modos de significar. A voz seria a subjetivação do tempo que a linguagem reteria do corpo. Pensar a voz, nessa perspectiva, significa situar o sentido, o sujeito como a impossibilidade da totalidade, da unidade, da verdade. A voz, o discurso e o sujeito se pressupõem mutualmente, o que faz com que a escuta seja múltipla, transversal. 


\section{Considerações finais}

A reflexão aqui proposta buscou erigir uma noção de voz, a partir de uma discussão que considere a constituição desse objeto em estreita relação com a linguagem, já que, conforme o diz Meschonnic (2009), a visão de linguagem que sustentamos é o nosso retrato, ou seja, mostra a forma como concebemos a língua/linguagem, a subjetividade, a intersubjetividade, a relação entre subjetividades, a relação da linguagem com o homem, da linguagem com a cultura, com a sociedade.

A linguagem concebida como uma antropologia histórica nos coloca diante da consideração de que a linguagem constitui o homem e a sociedade, de maneira que conforme afirma Benveniste (2005), não atingimos jamais o homem separado da linguagem, encontramos, contudo, um homem falando com outro homem, pois "a linguagem ensina a própria definição de homem" (p. 285). Dessa forma, "é na linguagem e pela linguagem que o homem se constitui como sujeito" (p. 286). No entanto, não se emprega o "eu" a não ser dirigindo-se a um "tu", pois a condição de diálogo é constitutiva da pessoa. Caem, assim, "as velhas antinomias do 'eu' e do 'outro', do indivíduo e da sociedade” (p. 287). Logo, é na dialética que engloba os dois termos que um e outro se definem mutuamente.

A concepção de linguagem aqui apresentada, em sua radicalidade histórica, não concebe que algo possa preexistir à linguagem. Por isso, a voz não pode ser concebida senão em sua constituição intrínseca com a linguagem. A voz e a linguagem configuram-se assim como o significante e o significado do signo em Saussure. É na relação mútua entre ambas que se constitui a subjetividade. Por isso, não se pode separar linguagem, voz e subjetividade.

A análise da voz não é a mesma, entretanto, no texto falado e no texto escrito. Isso não significa, porém, que concebo aqui a relação entre fala e escrita de forma dicotômica. Pelo contrário, na esteira de Meschonnic, há uma tripartição, a fala, a escrita e a oralidade. Essa última estaria presente nas duas outras. O que é acessível ao falado passa necessariamente para o escrito por uma poética que situa os modos de significância.

Ao considerar a voz na análise dos textos e das obras, passa-se a observar os elementos prosódicos e acentuais que figuram não mais como um nível, mas como transversais a todos os outros níveis da linguagem, morfológico, sintático, lexical. Busca-se, assim, considerar as relações daquilo que Meschonnic chama de uma paradigmática e de uma sintagmática do texto. Assim, a construção da significância não está somente atrelada a uma leitura linear, que considera as sucessividades nos textos e nas obras, mas também a uma leitura que busca outras relações, ditas paradigmáticas, $\mathrm{e}$ que constroem uma rede de significâncias, de relações múltiplas. 
A análise da voz de um texto, de uma obra nos mostra que mais do que dizer, a obra faz alguma coisa, o que nos leva a subverter a separação tão conhecida entre semântica, pragmática e estética. Todos os níveis de linguagem são englobados no processo de construção de significância de um texto, de uma obra, cuja produção trata-se de uma ação sobre o mundo. Assim, podemos dizer que essa análise coloca o analista em uma situação de escuta da enunciação.

Essa atividade de escuta em que se coloca o analista para observar a voz de um texto, de uma obra, mostra que porque essa significância é infinita, na medida em que sempre há a possibilidade de construir novos sentidos, novas leituras, e que sempre há novos textos, novas obras, novos sistemas de discurso, a pesquisa da voz é aberta, é infinita. Não se pode dizer tudo sobre a voz, pois as novas leituras, as novas análises, os textos e obras podem trazer novas questões, novas discussões, novas reflexões sobre o estudo da voz, sobre a poética da voz.

\section{La construction de la signification dans et par la voix}

\section{Résumé}

Ce travail est une invitation à réfléchir sur la construction de l'objet voix, à partir de la conception du langage comme anthropologie historique, proposée par H. Meschonnic (2009), dans la continuité de la pensée de F. de Saussure et d'É. Benveniste. Pour ce faire, cette recherche offre premiè- rement une discussion sur la relation, telle que conçue ici, entre voix et langage, afin de constituer un point de vue théorique à la réflexion sur ceu$x$-ci. Puis, la relation entre sons et sens est problématisée, considérant la perspective adoptée dans ce travail. Enfin, est interrogée la construction de la signifiance, dans et par la voix, dans des textes et œuvres. Cette réflection nous conduit à envisager le rythme, les rimes, les échos prosodiques, le silence, dans un exercice d'écoute de l'énonciation.

Mots-clé: Langage. Voix. Son. Sens. Signifiance.

\section{Notas}

1 Todas as traduções apresentadas no texto foram feitas por mim. A versão original será apresentada em nota. “[...] l'anthropologie du rythme, du langage, demande une anthropologie historique de la voix."

2 "[...] la voix, qui semble l'élément le plus personnel, le plus intime, est, comme le sujet, immédiatement traversé par tout ce qui fait une époque, un milieu, une manière de placer la littérature, et particulièrement la poésie, autant qu'une manière de se placer."

3 Ver Meschonnic (1982).

4 Simone de Beauvoir, Que peut la littérature? (1965), cité dans Fr. Vanoye, Expression communication, p. 151.

5 "La littérature ne commence qu'à ce moment-là, au moment où j'entends une voix singulière. [...] il n'y a pas de littérature s'il n'y a pas une voix, donc un langage qui porte la marque de quelqu'un. Il faut un style, un ton, une technique, un art, une invention [...] il faut que l'auteur m'impose sa présence ; et quand il m'impose sa présence, du même coup il m'impose son monde."

6 Alain Arnaud, Les Hasards de la voix, Flammarion, 1984, p. 26.

7 "Toute autre outil que la voix peut être réparé, tout autre instrument remplacé. Une voix perdue ne revient pas, brisée, elle ne se refait pas." 
8 "Les organes qui forment la voix font une espèce d'instrument à vent".

9 "La voix, premier des instruments, permet à la pensée de se muer en structures chantées ou parlées".

10 Robert Godel, Les Sources manuscrites du "Cours de linguistique générale » de Ferdinand de Saussure, Genève, Droz, 1957, p. 30.

11 Dépouiller le problème de tout ce qui est purement physiologique.

12 "[...] peut faire sa syntaxe, sa rythmique, peut faire sa typographie."

13 "[...] aucune rapport entre le contenu et le contenant dans le texte", "dans le seul esprit du lecteur que réside cette union, et non dans le poème".

14 É importante frisar que a denominação de "semântico sem semiótico" diz respeito a um recorte metodológico. Não se nega, pois, a existência de unidades, mas essas são consideradas na perspectiva de uma imbricação mútua com o discurso.

15 "Du point de vue linguistique, oral ou écrit, un texte reste un texte."

16 In: Oral poetry.

17 A expressão "significância" é utilizada novamente por Benveniste, no texto "O aparelho formal da enunciação", publicado no Problemas de Linguística Geral II. Agradeço a Heloísa Monteiro Rosário por essa ressalva.

18 " $[. .$.$] et, si l'on cherche dans l'œuvre de chaque$ poète une personnalité, on ne s'étonnera pas de rencontrer des prosodies personnelles."

19 "[...] même redondan[t] (ce qui est fréquemment le cas) [...] appor[t] des affirmations qui ne sont pas fournies par l'énoncé et dont on peut se demander si elles ne sont pas en fait l'essentiel du message."

20 Geneviève Calame-Griaule, Ce qui donne du goût aux contes, Littérature, $\mathrm{n}^{\circ} 45$, février 1982 , p. 50. La métaphore du goût pour le geste rejoint exactement celle de ta'am, "saveur ", «sens ", pour désigner l'accentuation biblique, c'est-à-dire le primat rythmique-prosodique dans le sens.

21 Jacques Cosnier, dans Jacques Cosnier-Alain Berrendonner-Jacques Coulon-Catherine Orecchioni, Les voies du langage, communications verbales, gestuelles et animales, préf. De Didier Anzieu, Dunod, 1982, p. 286.

22 "Ni un auxiliaire, ni un dérivé mais un associe qui lui est étroitement intrinqué pour former le langage naturel ainsi composé de trois sous-systèmes majeurs : le verbal, le vocal, le gestuel”.

\section{Referências}

BENVENISTE, Émile. Coup d'œil sur le développement de la linguistique. In :

Problèmes de linguistique générale, 2. Paris : Galimard, 1974a. p. 18-31.

Da subjetividade na linguagem. In: Problemas de lingüística geral I. Campinas: Pontes, 2005. p. 284-293.

Semiologia da língua. In:

Problemas de lingüística geral II. Campinas: Pontes, 2006a. p. 43-67.

. A forma e o sentido na linguagem. In:__. Problemas de lingüística geral II. Campinas: Pontes, 2006b. p. 220-244.

CAVARERO, Adriana. Vozes plurais: filosofia da expressão vocal. Belo Horizonte: Editora UFMG, 2011.

DERRIDA, Jacques. A voz e o fenômeno: introdução ao problema do signo na fenomenologia de Husserl/ Jacques Derrida. Tradução de Lucy Magalhães. Rio de Janeiro: Jorge Zahar, 1994.

FLORES, Valdir do Nascimento; SURREAUX, Luiza Milano. A voz e a enunciação. In: NEUMANN, Daiane; DIEDRICH, Marlete Sandra (Org.). Estudos da linguagem sob a perspectiva enunciativa. Passo Fundo: Méritos, 2012. p. 81-100.

FÓNAGY, Ivan. La vive voix. Paris : Payot, 1983.

LE BRETON, David. Éclats de voix. Une antrhopologie des voix. Paris : Éditions Métailié, 2011.

MESCHONNIC, Henri. Qu'entendez-vous par oralité?. Langue Française, n. 56, p. 6-23, 1982. Disponível em: <http://www.persee.fr/ web/revues/home/prescript/article/lfr_00238368_1982_num_56_1_5145>. Acesso em: $1^{\mathrm{o}}$ jun. 2013.

. Politique du rythme. Lonrai, França : Éditions Verdier, 1995. 
La rime et la vie. France: Éditions Verdier, 1989/ Gallimard, 2006.

. Critique du rythme: antropologie historique du language. Lonrai, França: Éditions Verdier, 2009.

Une Déclaration universelle des droits des langues et des cultures. In: Dans le bois de la langue. Paris : Editions Laurence Teper, 2008. p. 221-223.

PARRET, Herman. La voix et son temps. Bruxelles : Éditions De Boeck Université, 2002.

SAUSSURE, Ferdinand de. Curso de linguística geral. São Paulo: Cultrix, 2004.

ZUMTHOR, Paul. Introdução à poesia oral. São Paulo: Hucitec, 1997. 